\title{
AS REMISSÕES EM DICIONÁRIOS ELETRÔNICOS DE LÍNGUA PORTUGUESA: ONTOLOGIA E HIPERLINKS
}

\author{
Michelle Machado de Oliveira Vilarinho* \\ Enilde Faulstich *
}

\begin{abstract}
Resumo: O objeto de estudo são as remissões, a fim de identificar a estrutura e a função nas obras lexicográficas em formato eletrônico. Diante de nossa intenção de propor um modelo de dicionário eletrônico em pesquisas futuras, percebemos a necessidade de analisar criteriosamente a organização das remissões em dicionários eletrônicos da língua portuguesa, produzidos no Brasil. Utilizamos o método descritivo-comparativo, de modo que o objeto de estudo foi avaliado no Dicionário eletrônico Houaiss da Língua Portuguesa (2009) e no Novo Dicionário Aurélio versão eletrônica (2009). O referencial teórico se baseia em conceito de remissões apresentado por Faulstich (1993) e em definições de ontologia, hipertextos e hiperlinks. O resultado parcial da pesquisa revela que as remissões auxiliam na construção de ontologias, uma vez que esses recursos fornecem pistas na identificação das relações lexicais de forma sistêmica. As remissões enriquecem as obras lexicográficas por representarem caminhos que o consulente pode percorrer para compreender os significados de lexemas. Além disso, as obras em formato eletrônico disponibilizam ferramentas facilitadoras de acesso às remissões, visto que o usuário pode consultar os lexemas de modo mais ágil, ao percorrer os hiperlinks.
\end{abstract}

Palavras-chave: Remissões; dicionários eletrônicos; hiperlinks; ontologia.

* Universidade de Brasília. 


\begin{abstract}
The objective of this study is to identify the structure and the function of cross-references on electronic lexicographic works. As our intention is to postulate an electronic dictionary model on future researches, we realized the need to cautiously analyse crossreference organizations of Portuguese electronic dictionaries developed in Brazil. We used the descriptive-comparative method, so that the object of study was assessed in the electronic Dictionary Houaiss da Língua Portuguesa (2009) and in the electronic version of the Novo Dicionário Aurélio (2009). The theoretical framework is based on the concept of cross-references presented by Faulstich (1993) and on ontology, hypertext and hyperlink definitions. Partial results of the research show that cross-references support the ontology construction, since these resources provide clues to the identification of lexical relations on a systemic perspective. Crossreferences enrich lexicographic works for they represent ways in which the person consulting a dictionary may investigate, in order to understand the meaning of lexemes. Besides, works on an electronic format provide available tools to make easier the access to cross-references, since the user may consult lexemes faster, and follow the hyperlinks.
\end{abstract}

Keywords: Cross-references; electronic dictionary; hyperlinks; ontology.

\title{
Introdução
}

O dicionário tem como uma de suas finalidades principais a apresentação do significado das palavras. Um dos recursos lexicográficos utilizados que auxiliam na compreensão do significado são as remissões, conhecidas também como referências cruzadas, que analisamos no Dicionário eletrônico Houaiss da Língua Portuguesa (2009) e no Novo Dicionário Aurélio versão eletrônica (2009). Utilizamos o método descritivo-comparativo na pesquisa, com o objetivo de identificar a estrutura e a função das remissões nas obras lexicográficas em formato eletrônico. Diante da intenção de propor um modelo de dicionário eletrônico, futuramente, percebemos a necessidade de analisar criteriosamente a organização das remissões em dicionários 
eletrônicos da língua portuguesa produzidos no Brasil, e apresentamos neste artigo algumas reflexões sobre o assunto.

O artigo está dividido nas seções: 1) Os dicionários eletrônicos e a constituição das remissões; 2) As remissões no Dicionário eletrônico Houaiss da Língua Portuguesa (2009) e no Novo Dicionário Aurélio versão eletrônica (2009); 3) Dicionários eletrônicos: ontologia e remissões; 4) Considerações finais.

\section{Os dicionários eletrônicos e a constituição das remissões}

A sociedade moderna exige a criação de ferramentas que disponibilizem informações com rapidez por meio de recursos tecnológicos. Diante dessa exigência, surgiram os dicionários eletrônicos, que contêm recursos computacionais com ferramentas que ampliam o conteúdo dos repertórios lexicográficos. Esses repertórios são estruturados por meio de sistemas de Processamento de Língua Natural (PLN), de modo que possibilitem o acesso e a compreensão dos itens buscados pelo consulente. Essa compreensão é "a tradução de uma linguagem natural em uma linguagem artificial" (RASTIER et al., 1994, p. 10), sendo que a máquina processa os dados de linguagem artificial, e o homem os entende por serem disponibilizados em língua natural.

Os sistemas de PLN são capazes de gerar dicionários com ferramentas inovadoras, que possibilitam o acesso à informação de forma prática. Como exemplo desse processo, há o uso de hiperlinks ${ }^{1}$ na estruturação das remissões, os quais facilitam o percurso do consulente quando tenta compreender o significado dos lexemas.

Os dicionários eletrônicos sob análise são o Dicionário eletrônico Houaiss da Língua Portuguesa (2009) e o Novo Dicionário Aurélio versão eletrônica (2009), armazenados também

\footnotetext{
${ }^{1}$ Hiperlink é uma hiperligação, um liame, ou simplesmente uma ligação, dentro de um documento em hipertexto, a outras partes desse documento ou a outro documento. Adaptado de http://pt.wikipedia.org/wiki/, página visitada em 3/8/2013.
} 
em CD-ROM. A principal diferença entre os dicionários na versão impressa e na versão informatizada é que os eletrônicos possibilitam o acesso mais rápido aos lexemas de diferentes verbetes devido aos hiperlinks, que relacionam os dados entre si.

Nos repertórios lexicográficos eletrônicos, os dados constituídos por lexemas, abonações e exemplos - são transformados em hipertextos e apresentam-se relacionados por meio de hiperlinks. O hipertexto é um conjunto de dados ligados entre si, editado no computador. Esse conjunto de dados permite ao consulente seguir "outra ordenação no processamento da leitura que não seja, necessariamente, a que está proposta na superfície visual.” (XAVIER, 2009, p. 106). Nos hipertextos, as informações são organizadas em forma de redes; assim sendo, permitem consultas que não são hierárquicas e nem lineares necessariamente.

Os hiperlinks, por sua vez, são dispositivos informáticos que criam elos entre os dados. Os hiperlinks são constituídos por links, que são "mecanismos de referenciação digital", segundo Xavier (2009, p. 192). Nos dicionários eletrônicos, os hiperlinks vinculam diferentes lexemas, direcionando o consulente a outro(s) lugar(es) do hipertexto por meio de um clique no dispositivo informático, que o conduz a outro lexema, por serem relacionados entre si. As remissões das obras dicionarísticas na versão eletrônica são um exemplo de estruturas em hiperlinks.

Com base em Faulstich (1993, p. 174), remissão é o processo de remeter a informação de um ponto a outro, e esse ponto de chegada é uma remissiva, que é

cada item léxico que possui conteúdo semântico próprio. É, formalmente, a unidade semântica contida numa definição, ou seja, aquela palavra que provoca no leitor a curiosidade de saber o que significa, para que ele possa melhor compreender o conteúdo definicional do termoentrada. Funcionalmente, as remissões se constituem em verdadeiros trajetos de reconstituição de significados. 
Entendemos que as remissóes complementam a definição, porque auxiliam o usuário na compreensão do significado de outro lexema relacionado ao anterior, por oferecerem caminhos a serem percorridos pelo consulente para atingir o objetivo. Assim, "caberá ao lexicógrafo funcionar como um guia dentro da própria obra a fim de abastecer o leitor de informação". (FAULSTICH, 1993, p. 92).

Além disso, essas referências cruzadas organizam campos léxicos, que são "uma estrutura paradigmática constituída por unidades léxicas que compartilham uma zona de significação comum em oposição imediata umas com as outras" (COSERIU, 1977 , p. 140). Essa zona de significação comum pode ser entendida como o conjunto de traços comuns que os lexemas repartem. As oposições dizem respeito aos traços distintivos, que diferenciam uns lexemas de outros. Por meio das remissões, os lexemas que apresentam traços comuns são linkados, quer dizer, fazem ligações entre si. Em consequência, "o lexicógrafo beneficia o usuário, ao estruturar, nocionalmente, a informação e, ao mesmo tempo, organizar campos léxicos" (FAULSTICH, 1993, p. 174).

Em 1916, Saussure afirmara que "as palavras que oferecem algo em comum se associam na memória e assim formam grupos dentro dos quais imperam relações muito diversas" (SAUSSURE, 1999, p. 143). Entre as relações que os lexemas formam entre si, o sistema de remissões explicita as relações lexicais, a saber, sinonímia, hiperonímia, hiponímia, holonímia, meronímia, antonímia e conceito conexo. Esse sistema, nos dicionários eletrônicos, é construído por meio de hiperlinks, os quais permitem o acesso rápido às relações lexicais e possibilitam a circulação entre lexemas, reorganizando, dessa forma, o conhecimento. 


\section{As remissões no Dicionário eletrônico Houaiss da Língua Portuguesa (2009) e no Novo Dicionário Aurélio versão eletrônica (2009)}

No Dicionário eletrônico Houaiss da Língua Portuguesa (2009) e no Novo Dicionário Aurélio versão eletrônica (2009), as remissões são apresentadas de diferentes maneiras com base em biperlink. Para compreender a organização dessas remissões, dirigimo-nos, nas obras, primeiramente à macroestrutura, e posteriormente à microestrutura, já que "uma remissão, como indicativo de relações nocionalmente ligadas, surge na microestrutura, mas vai ter reflexo na macroestrutura textual" (FAULSTICH, 1993, p. 91). Na macroestrutura, são registradas as formas de apresentação das referências cruzadas. Na microestrutura, há a apresentação desse recurso lexicográfico.

As formas de apresentação das remissões na obra de Houaiss (2009) são explicitadas na seção da macroestrutura "Detalhamento dos verbetes e outras informações". Quando um lexema tiver a definição contida em outro verbete, por ser um sinônimo ou quase sinônimo desse item lexical, a remissão geralmente é feita com abreviação "m.q.", que significa "mesmo que", e o lexema remissivo é destacado em caixa-alta, negrito e itálico. Nesse dicionário, as remissões são classificadas em 4 tipos: excludente, discreta, imperativa e genérica.

A remissão excludente aparece entre parênteses com uma rubrica ou com uma minidefinição para excetuar uma acepção. Como exemplo desse tipo de ocorrência, no verbete balázio, a remissão está constituída da seguinte forma: "m.q. BALAÇO (exceto FUTB)", que faz referência à palavra-entrada balaço, e a informação entre parênteses serve para explicar a necessidade da exclusão da acepção da rubrica futebol.

A remissão discreta ocorre, geralmente, em acepções da linguagem informal, tabuística ou regional registradas no dicionário. Nessa remissão, outro verbete é citado, de modo que 
pode aparecer sem os recursos do uso de "m.q." ou "ver", por não ser desejável, em tais casos, deixar patente a sugestão de que o leitor vá ao outro verbete; ou pode ser feita, em meio a um texto de definição, com destaque na palavra ou sintagma para o qual a atenção deve se voltar. Um exemplo desse tipo de remissão encontra-se no texto definitório do verbete tabuísmo, no qual aparece o lexema mijar destacado em itálico, que remete ao verbete por meio de links, sem ter indicação explícita de remissão. Quando o consulente clica no link mijar, aparece o verbete mijar. Nesse verbete, há a acepção $1 \mathrm{com}$ a rubrica uso informal com remissão "m.q.", remetendo para o verbete urinar por meio da remissão excludente.

A remissão imperativa é utilizada quando o dicionário elege um lexema em detrimento de outro para registrar a definição. Nesse caso, a remissão é introduzida pelo lexema "ver". A eleição de determinado lexema para a remissão ocorre por motivos diversos, como maior correção, entradas em português em lugar de palavras ou locuções estrangeiras, ou palavras técnicas preferidas. Na acepção 1 do verbete belostomídeo, que é um termo da entomologia, a remissão aparece da seguinte forma: "ver BELOSTOMATÍDEO".

Também os autores do dicionário usam a remissão "ver" para apresentar sinônimos, antônimos, homônimos e parônimos, e nos verbetes de elementos mórficos de composição, prefixos, sufixos e outros. Um exemplo dessa remissão pode ser encontrado no subcampo "sinônimos e variantes" do verbete carapanta, no qual há a informação "ver sinonímia de bebedeira", sendo que o lexema em itálico constitui um hiperlink. Ademais, nos verbetes, quando a abreviatura "Obs." é apresentada, aparece acompanhada de remissão indicada pela abreviatura "cf.", conforme ocorre no verbete lactante.

A remissão genérica indica em que local da alfabetação estão as definições procuradas pelo consulente, para que a forma de apresentação dos verbetes seja concisa, ao invés de registrar 
longa lista de verbetes remissivos compostos por variantes. $\mathrm{Na}$ constituição desse tipo de remissão, a palavra-entrada aparece grafada apenas com parte da palavra, o que pode causar dúvidas. Nessa entrada, há uma forma variante do lexema, que remete a outro verbete, que é o que define o item lexical consultado. Desse modo, se o consulente procurar, por exemplo, algumas palavras grafadas com -ct, em que o -c seja mudo, ele será informado de que o item lexical está registrado na obra com grafia sem a letra c, como podemos ver na figura a seguir:

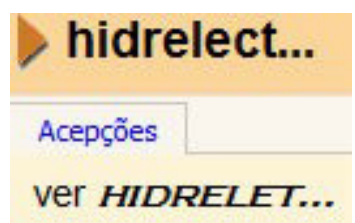

Figura 1: verbete bidrelect...

\section{Fonte: (DICIONÁRIO ELETRÔNICO HOUAISS \\ DA LÍNGUA PORTUGUESA, 2009, com adaptações)}

Observamos que "hidrelect..." constitui uma palavraentrada, uma remissão "ver HIDRELET", e, ao clicar na referência cruzada, o leitor é conduzido ao verbete hidreletricidade.

As remissões genéricas no dicionário aparecem assim: abce... ver ABSCE...; abci... ver ABSCI...; acci... ver ACI...; acupunct... ver ACUPUNT...; contact... ver CONTAT...; contract... ver CONTRAT...; dact... ver tb. DAT...; electr... ver ELETR...; hidrelect... ver HIDRELET...; humid... ver UMID ...; lact... ver tb. LAT...; omni... ver ONI...; sintact... ver SINTAT...; tact... ver TAT...; termelectr... ver TERMELETR...; termoe... ver TERME...; e termoelectr... ver TERMELETR.... Diante disso, deduzimos que esse tipo de remissão é empregada para atenuar dúvidas da grafia de lexemas e de termos.

Além desses quatro tipos de referências cruzadas, o dicionário eletrônico Houaiss da Língua Portuguesa possui outras formas de remissões, quais sejam: 
a) lexemas entre parênteses, a fim de apresentar:

i) Minidefinição da acepção para a qual remete o leitor, para que ele compreenda em que campo lexical está inserido o lexema, e para permitir que ele, se desejar, leia a definição completa, que se encontra em outro verbete. $\mathrm{O}$ verbete representado a seguir ilustra essa forma de remissão:

\section{gestual \\ Acep̧̧ões \\ - adjetivo de dois gêneros \\ 1 relativo a gesto ('movimento')}

Figura 2: verbete gestual

Fonte: (DICIONÁRIO ELETRÔNICO HOUAISS

DA LÍNGUA PORTUGUESA, 2009, com adaptações)

Nesse verbete, a remissão ('movimento') indica que, ao clicar na palavra gesto, abre-se o verbete, que na acepção 1 remete a "m.q." GESTICULAÇÃO ('ato'), e na acepção 2 diz que é "movimento do corpo...".

ii) Referência à rubrica que delimita o campo semântico da acepção pertinente da palavra ou locução para a qual há remissão.

iii) Classificação taxonômica do ser ou seres para os quais está remetendo, no caso de verbetes de botânica e zoologia. Um exemplo disso ocorre no verbete facoquero, em que, além da remissão "m.q.", há, entre parênteses, a classificação taxonômica da mastozoologia "Phacochoerus aethiopicus", conforme pode ser visto na figura a seguir: 


\section{facoquero Ontoépia: ê}

\section{Acepções}

substantivo masculino

Rubrica: mastozoologia.

m.q. IAVALI-AFRICANo (Phacochoerus aethiopicus)

Figura 3: verbete facoquero

Fonte: (DICIONÁRIO ELETRÔNICO HOUAISS

DA LÍNGUA PORTUGUESA, 2009, com adaptações)

b) Números entre parênteses, a fim de referir:

i) Acepções anteriores ou posteriores dentro de um mesmo verbete, como ocorre na acepção 7 do verbete abacaxi; vejamos:

\section{substantivo de dois gêneros}

Rubrica: etnologia.

6 indigena pertencente ao grupo dos abacaxis

\section{adjetivo de dois gêneros}

Rubrica: etnologia.

7 relativo a abacaxi (acp. 6) ou aos abacaxis

Figura 4: verbete abacaxi

Fonte: (DICIONÁRIO ELETRÔNICO HOUAISS

DA LÍNGUA PORTUGUESA, 2009, com adaptações)

ii) Acepções do verbete a que pertencem as locuções, como está na locução algodão hidrófilo do verbete algodão, em que há indicação do significado da acepção 3:

\section{- a. hidrófilo}

$$
\text { ver ALGODĀO (acp. 3) }
$$

Figura 5: verbete algodão

Fonte: (DICIONÁRIO ELETRÔNICO HOUAISS

DA LÍNGUA PORTUGUESA, 2009, com adaptações) 
c) Abreviatura "red." mais lexema em caixa-alta, para indicar que a locução substantiva do tipo substantivo mais adjetivo, ou substantivo mais substantivo, foi reduzida, de modo que a palavra-entrada é o segundo elemento da locução. $\mathrm{O}$ verbete celular possui exemplo desse tipo de remissão:

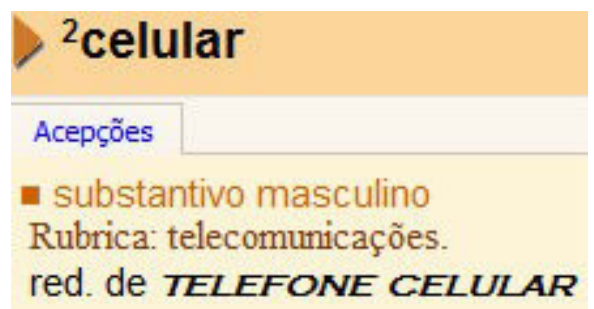

Figura 6: verbete celular

Fonte: (DICIONÁRIO ELETRÔNICO HOUAISS

DA LÍNGUA PORTUGUESA, 2009, com adaptações)

Outra forma de remissão que não foi explicada na macroestrutura do dicionário Houaiss, embora apareça na obra, é a indicação do lexema que não é muito utilizado. Nesse caso, a remissão encontra-se em caixa alta, mas não vem acompanhada da abreviatura "m.q.", mas sim da expressão "menos usada que", sendo que "usada" aparece abreviado, como ocorre no verbete beduim, que remete a beduíno:

\section{beduim}

lu-ím\s.m. (c1541) menos us. que BEDUíNo

Figura 7: verbete beduim

Fonte: (DICIONÁRIO ELETRÔNICO HOUAISS

DA LÍNGUA PORTUGUESA, 2009)

Como vimos, no Dicionário eletrônico Houaiss da Língua Portuguesa, as remissões são sofisticadas e, por isso, as consideramos complexas. 
$\mathrm{Na}$ continuidade de nossas reflexões, vamos estabelecer um paralelo entre o Dicionário eletrônico Houaiss (2009) e o Novo Dicionário Aurélio versão eletrônica (2009), para chegar a algumas conclusões acerca das remissões lexicográficas.

$\mathrm{Na}$ macroestrutura do Novo Dicionário Aurélio versão eletrônica (2009), há o menu "ajuda", com a seção "Verbete entenda sua estrutura". Subordinada a essa seção, há a subseção "remissiva", que apresenta as informações sobre a constituição das referências cruzadas. A remissão pode ser identificada pela abreviatura $\mathrm{V}$. seguida por lexia simples ou composta, em itálico. Esse recurso lexicográfico tem a função de conduzir o leitor a um verbete, a uma locução ou a uma definição diferentes. Dessa forma, o consulente poderá encontrar a definição com o significado similar ou complementar ao da palavra no contexto, ou poderá confrontar com outras definições que elucidarão melhor esse significado.

Outra forma de registrar a remissão é " $\sim \mathrm{V}$." seguido pelo lexema em itálico e em negrito, para remeter à locução na qual uma das palavras encabeça o verbete que está sendo consultado (geralmente como adjetivo). Nesse caso, essa palavra é substituída por um travessão seguido de um indicador de flexão de gênero ou de número. Um exemplo desse tipo de ocorrência está na acepção 1 do verbete dependurado (ilustrado na figura a seguir): a remissão indica a locução olbos dependurados, dentro do verbete olbo:

\section{dependurado}

\section{[Part. de dependurar.]}

Adjetivo.

1. Que se dependurou; pendurado. V. olhos $-s$.

Figura 8: verbete dependurado

Fonte: (NOVO DICIONÁRIO AURÉLIO

VERSÃO ELETRÔNICA, 2009, com adaptação) 
Quando há a necessidade de indicar as acepções de uma palavra para direcionar a remissão, os números das acepções relacionados com a remissão aparecem entre parênteses, conforme ocorre na acepção 3 do verbete abafo:

\section{abafo}

[Dev. de abafar ${ }^{2}$.]

Substantivo masculino.

1. Agasalho (6).

2. Afeto, afago.

3. v. abafamento (2 e 4).

Figura 9: verbete abafo

Fonte: (NOVO DICIONÁRIO AURÉLIO VERSÃO ELETRÔNICA, 2009)

Notamos que, na acepção 1 desse verbete, há um erro de sistematização, pois a remissão não apresenta a abreviatura $\mathrm{V}$. Assim, embora na macroestrutura da obra sejam apresentadas duas maneiras de estabelecer as remissões, identificamos que esse recurso lexicográfico é feito também com a indicação de acepção entre parênteses, como no verbete abaianada:

\section{abaianada}

(a-i). [F. subst. de abaianado.]

Substantivo feminino.

1. Bras. N.E. Peça de zabumba (2), de ritmo rápido, caracterizada sobretudo pelo toque rufado do tarol.

Figura 10: verbete abaianada

Fonte: (NOVO DICIONÁRIO AURÉLIO VERSÃO ELETRÔNICA, 2009)

Nesse verbete encontra-se uma remissão ao verbete zabumba, como vemos a seguir: 
[Voc. onom, ou do conguês bumba.]

Substantivo masculino e feminino.

1. Mús. V. bombo (1):

"Perguntei que contentamento se expandia nos zabumbas, e clarinetes, e morteiros que atroavam montes e vales." (Camilo Castelo Branco, Doze Casamentos Felizes, p.

50); "A banda de couro, constituida da zabumba, das cinco caixas, dos dois flautins .... e do triânngulo, executava seus toques monótonos." (Bernardo Elis, Veranico de

Janeiro, p. 31),

2. Mús. V. terno de zabumba.

Substantivo de dois gêneros.

3. Mús. Zabumbeiro:

"vigilante Rômulo, .... uma besta, grandalhão, último na ginástica ..... último nas aulas, .... mas exercendo no colégio .... as complexas e delicadas funções de zabumba da

banda." (Raul Pompeia, O Ateneu, p. 51).

4. Bras, Zool. V. camarão-castanho.

Substantivo masculino.

5. Bras. CE Bot. V. estramônio. [Cf. zambumba.]

Figura 11: verbete zabumba

Fonte: (NOVO DICIONÁRIO AURÉLIO VERSÃO ELETRÔNICA, 2009)

A acepção 2 desse verbete - lembremos que é uma remissão no verbete abaianada - apresenta outra remissão ao verbete terno de zabumba. Em terno de zambumba, as acepções $1,2,4$ e 5 remetem o leitor a outros verbetes. A acepção 3 não tem remissão, mas é definida por sinônimo. O resultado de um verbete só com remissões e com definição por sinônimo promove a circularidade, e não leva o consulente ao significado buscado imediatamente; apenas fornece mais caminho para que possa percorrer na obra. No entanto, se o consulente clicar nas remissões indicadas, conseguirá entender o significado destas, pois os verbetes indicados para consulta apresentam definições claras. Um exemplo disso é a forma como a definição da acepção 1 está registrada no verbete bombo. Acrescentamos, por outro lado, que na acepção 2 o autor remete à homonímia do verbete bombeiro. Essa forma de remissão não está prevista na macroestrutura, o que é uma incoerência da obra. 
bombo

[Do it, bombo.]

Substantivo masculino.

1. Mús. Tambor (2) de grandes dimensões e sonoridade grave, percutido com macetas, tocado com as peles em posição vertical, e usado em bandas militares e orquestras, bem como para marcar o ritmo na música popular. [Var.: bumbo. Sin.: zabumba ou zambumba, caixa grande; bumba (CE), zambê (RN).]

2. Bombeiro? 2 .

3. Tip. Tambor (12).

Figura 12: verbete bombo

Fonte: (DICIONÁRIO AURÉLIO VERSÃO ELETRÔNICA, 2009)

Ainda na seção "Verbete - entenda sua estrutura", há uma explicação sobre outro componente do verbete, que é a achega. Esse recurso, apresentado entre colchetes, inclui informação adicional à definição, podendo ser de natureza explicativa, comparativa [Cf., sinônimos, antônimos etc.], gramatical [flexões, conjugação verbal etc.], entre outras. Percebemos que, em alguns verbetes, a achega exerce a mesma função de uma remissão. A acepção 5 do verbete zabumba e a acepção 1 do verbete bombo possuem achegas. Esta acepção indica a variante bombo e os sinônimos zabumba ou zambuba, caixa grande, bumba e zambê. Ao clicar na achega do verbete $z a b u m b a$, há remissão ao verbete zambumba:

\section{zambumba}

\section{Substantivo feminino.}

1. Mús. V. bombo (1).

2. Bot. V. estramônio.

3. Zool. v. camarão-castanho. [Cf. zabumba.]

Figura 11: verbete zambumba

Fonte: (NOVO DICIONÁRIO AURÉLIO VERSÃO ELETRÔNICA, 2009)

A achega faz referência ao verbete zabumba. Esse recurso serve como uma complementação do significado que pode ser introduzida por meio da abreviatura Cf., que é um caminho a percorrer, além de apresentar variantes e relações lexicais. 
Diante dos recursos que o Novo Dicionário Aurélio utiliza para as remissões, o consulente pode-se perder, pois as remissões não obedecem à sistemática prevista na macroestrutura, e há vários casos em que a circularidade dificulta o entendimento do significado. As remissões servem para complementar o significado, ampliar o conhecimento linguístico e cultural, e não para substituí-los.

Acreditamos que "a validade de uma remissão pode ser avaliada de acordo com a relação que cada uma das remissivas estabelece com a entrada, ou que elas estabelecem entre si no corpo da definição" (FAULSTICH, 1993, p. 92). Mediante essa afirmativa, as remissões nas obras sob análise são válidas por terem relações com a palavra-entrada e com os lexemas no corpo na definição. No entanto, cabe aos lexicógrafos melhorar a técnica de remeter de uma palavra a outra nos dicionários, assim como padronizar a forma de estruturar a relação entre uma remissiva e outra. No dicionário de Houaiss (2009), existem diversas formas para apresentar esse recurso lexicográfico que podem ser simplificadas, com vistas a que a consulta ao recurso se torne mais amigável. No Novo Dicionário Aurélio versão eletrônica (2009), é necessário organizar, na macroestrutura, a indicação da remissão antecedida da abreviatura $V$. Não é possível distinguir remissivas de achegas, visto que ambas cumprem a mesma função em alguns verbetes.

Feito o estudo das remissões nos dois dicionários eletrônicos, apresentaremos, na próxima seção, características ontológicas, que podem auxiliar na estruturação das remissões.

\section{Dicionários eletrônicos: ontologia e remissões}

A constituição dos dicionários eletrônicos é ontológica. Em vista disso, é necessário compreender a definição, a estrutura e a funcionalidade de ontologias nos dicionários. Merece destaque a origem do termo ontologia, que vem do grego óntos, 'ser', e logos - 'palavra', 'discurso', 'razão'. Ontologia designa, de forma genérica, 
o estudo que se preocupa "com a identificação das características comuns a todos os seres" (MOREIRA, 2007, p. 10). O termo original surgiu na Filosofia e corresponde à palavra aristotélica "categoria", usada para classificar alguma coisa (ALMEIDA \& BAX, 2003, p. 8).

Nos estudos sincrônicos, o tema 'ontologia' vem sendo discutido e aplicado não apenas na Filosofia, mas em diversas áreas do conhecimento, tais como Sistemas de Informação, Linguagem e Cognição, Inteligência Artificial, Banco de Dados, entre outras. Na literatura especializada, há definições diversas para ontologia e tipos variados de aplicação nas áreas de conhecimento, de modo que diferentes definições podem ser encontradas em uma mesma área.

No quadro a seguir, relacionamos definições de ontologia, segundo as áreas do conhecimento:

\begin{tabular}{|l|l|}
\hline Área do conhecimento & \multicolumn{1}{c|}{ Ontologia } \\
\hline Sistemas de Informação & $\begin{array}{l}\text { Um conjunto de conceitos e termos que podem ser } \\
\text { usados para descrever alguma área do conhecimento ou } \\
\text { construir uma representação para o conhecimento } \\
\text { (SWATOUT \& TATE, 1999). }\end{array}$ \\
\hline Base de dados & $\begin{array}{l}\text { Conhecimento genérico que pode ser reusado em } \\
\text { aplicações de tipos diferentes (MEERSMAN, 2002). }\end{array}$ \\
\hline Inteligência Artificial & $\begin{array}{l}\text { Caracterização axiomática do significado do vocabulário } \\
\text { lógico (GUARINO, 1997). } \\
\text { Definição dos tipos de coisas que existem ou podem } \\
\text { existir em um mesmo domínio (SOWA, 2000). } \\
\text { Uma especificação formal explícita de uma conceituação } \\
\text { compartilhada (GRUBER, 1993, p. 199). }\end{array}$ \\
\hline Linguagem e Cognição & $\begin{array}{l}\text { Ontologia refere-se a tudo que existe no mundo } \\
\text { composto por objetos, mudanças e relações entre eles. } \\
\text { Pode ser baseada no mundo, na mente/intelecto, na } \\
\text { cultura ou na linguagem (DAHLGREN, 1995). }\end{array}$ \\
\hline
\end{tabular}

Fonte: (PINHEIRO, 2004, p. 19-20, com adaptações)

Uma das definições de ontologia mais conhecidas e aplicáveis aos mais variados contextos é "uma especificação formal explícita de uma conceituação compartilhada" (GRUBER, 1993, p. 199). O autor quer dizer que 'formal' corresponde a ser lida por máquina; 'explícita' 
significa que os conceitos usados e as delimitações de uso são estabelecidos de modo explícito na linguagem documentária; conceituação, que depende de uma visão de mundo, descreve a extensão e a intenção dos conceitos que se deseja representar; 'compartilhada' significa que a expressão apresenta um conhecimento consensual de uma comunidade.

As ontologias linguísticas são definidas por Magnini \& Speranza (2002, p. 43) como:

grandes recursos lexicais que organizam a maioria das palavras de uma língua, e, ao mesmo tempo, fornecem uma estrutura ontológica, na qual a ênfase principal está nas relações entre os conceitos; ontologias linguísticas podem ser vistas tanto como um tipo específico de banco de dados lexicais e como um tipo particular da ontologia.

Para compreender a estrutura de uma ontologia, podemos considerar a afirmativa subsequente:

Uma ontologia pode ter uma variedade de formas, mas necessariamente inclui um vocabulário de termos e alguma especificação de seu significado. Isto inclui definições e uma indicação de como conceitos são interrelacionados, os quais impõem coletivamente uma estrutura sobre o domínio e restringe as possíveis interpretações do termo. (USCHOLDE \& JASPER, 1999)

Assim sendo, as ontologias podem ser estruturadas utilizando variados tipos de ferramentas; no entanto, será sempre composta por conjuntos de conceitos acompanhados de suas respectivas definições e organizados de forma relacionada, para que seja compreendido o seu significado e sua posição no sistema classificatório. A ontologia pode ser caracterizada "por um sistema classificatório bem delineado e definido, que permite ter estrutura interna clara e passível de formalização e entendimento para a máquina e um vocabulário de um domínio, formado essencialmente por conceitos e por uma rica rede de relações" (GONÇALVES \& SOUZA, 2008). 
Diversos autores observam que "as ontologias são utilizadas em projetos de domínios como gestão do conhecimento, comércio eletrônico, processamento de linguagens naturais, recuperação da informação na Web, de cunho educacional, entre outros." (ALMEIDA \& BAX, 2003, p. 9). Desse modo, as ontologias desempenham papéis relevantes nas diversas áreas do conhecimento devido às suas finalidades, pois "servem como um meio para a representação de informações que contêm um caráter semântico comum, que podem ser aplicadas em situações diversas do mundo real" (SANTOS \& VALE, 2008). Permitem aos múltiplos agentes compartilhar o conhecimento, ajudar pessoas a compreender melhor certa área de conhecimento e possibilitar um consenso no entendimento de um domínio específico.

Os componentes básicos de uma ontologia são as classes, organizadas em uma taxonomia; as relações que representem o tipo de interação entre os conceitos de um domínio; os axiomas, usados para modelar sentenças sempre verdadeiras; e as instâncias, que são espaço e tempo determinados, utilizadas para representar elementos específicos, que são os próprios dados (GRUBER, 2005).

Essa explicação, acerca da estrutura de dicionário eletrônico e de ontologia, comprova que os dicionários eletrônicos são de base ontológica, visto que "o uso de ontologias tem-se mostrado um meio eficiente de representação de conceitos semanticamente relacionados, servindo não só aos propósitos de sistemas de banco de dados, como também para o Processamento de Língua Natural." (KASAMA et al., 2010, p. 44). Como esses dicionários são elaborados por meio de uso de PLN, podemos afirmar que definem, relacionam os lexemas por meio de redes de remissivas, e utilizam um formalismo o qual possibilita o tratamento computacional dos dados linguísticos.

Ontologia, como área do saber, classifica as entidades existentes ao estabelecer relações conceituais, ao definir propriedades e ao explicitar restrições. Na construção de uma ontologia, faz-se uma categorização dos conceitos e esses conceitos 
são relacionados entre si. A fim de identificar a aplicabilidade das ontologias em uma obra lexicográfica, percebemos que, no processo de o lexicógrafo estabelecer as remissões no dicionário eletrônico, criam-se categorias ontológicas, pois uma ligação é estabelecida por meio de hiperlinks que atuam nos lexemas de acordo com relações entre si. Esses links se justificam pelas relações lexicais que estruturam campos lexicais, que conectam os lexemas porque compartilham traços comuns, características que justificam as remissões.

Um projeto lexicográfico exige seleção de ordem linguística e restrições de ordem técnica, estabelecidas pelo lexicógrafo, para a elaboração do dicionário. No entanto, a perspectiva ontológica é útil porque auxilia na organização dos lexemas, de modo que explicita links para cada conceito. Esses links, que são utilizados nas conexões entre os conceitos relacionados, formam um conjunto, que deve ser coeso e interpretado como hiperlink, no todo da obra.

\section{Considerações finais}

Nossas reflexões têm o papel de demonstrar que as remissões auxiliam na construção de ontologias, ou que as ontologias são úteis na elaboração dos verbetes de dicionários, uma vez que se organizam de forma sistêmica e possibilitam que a arquitetura do dicionário seja pensada desde o início do projeto. É de conhecimento que as remissões enriquecem as obras lexicográficas, pois representam caminhos que o consulente pode percorrer para ampliar a compreensão do significado de lexemas e ampliar o conhecimento de mundo. Interessante é perceber que as obras com formato eletrônico disponibilizam ferramentas facilitadoras de acesso às remissões, o que deixa o leitor mais confortável ao percorrer os hiperlinks que "permitem realizar ágeis deslocamentos de navegação e [...] podem dinamizar a leitura". (XAVIER, 2009, p. 200). 
Os sistemas de PLN que armazenam os dicionários eletrônicos facilitam o acesso à informação, por apresentarem recursos variados que atendem às necessidades dos consulentes. A análise levada a cabo neste artigo nos permite observar que a lexicografia brasileira ainda depende de bons projetos, feitos por pesquisadores treinados para esse fim. Um dicionário é um material didático útil para a faixa etária a que se dirige. É um tesouro que revela o que diz e o que pensa uma sociedade.

\section{Referências}

ALMEIDA, Maurício Barcellos; BAX, Marcello Peixoto. Uma visão geral sobre ontologias: pesquisa sobre definições, tipos, aplicações, métodos de avaliação e de construção. Ciência da Informação: Brasília, v. 32, n. 3, p. 7-20, set./out. 2003.

COSERIU, Eugenio. Teoria da linguagem e linguística geral. Rio de Janeiro: Presença; São Paulo: Edusp, 1977.

DAHLGREN, K. A Linguistic ontology. Internacional Journal on Human Computer Studies, v. 43, 1995.

FAULSTICH, Enilde. Rede de remissivas em um glossário técnico. In: MACIEL, A. M. B. (Org.). Cadernos do IL. Porto Alegre: UFRGS, 1993. p. 91-98.

FERREIRA, Aurélio Buarque de Holanda. Novo dicionário Aurélio da língua portuguesa - Século XXI. 4. ed. Editora Positivo, 2009.

GONÇALVES, Julia Aparecida; SOUZA, Renato Rocha. As relações semânticas em ontologias: contribuição para análise conceitual. In: SEMINÁRIO DE PESQUISA EM ONTOLOGIA NO BRASIL, 2008. Anais... Niterói: UFF, 2008.

GRUBER, Thomas Robert. A translation approach to portable ontology specifications. Knowledge Acquisition, s. 1., v. 5, n. 2, p. 199-220, jun. 1993.

GRUBER, Thomas Robert. What is an ontology? [S. n: s. 1.]: 2005. Disponível em: <http://www-ksl.stanford.edu/kst/what-is-an-ontology. html >. Acesso em: 10 nov. 2009. 
GUARINO, N. Semantic matching: formal ontological distinctions for information organization, extraction, and integration. Itália: Springer Verlag: 1997. Disponível em: <http://www.ladseb.pd.cnr.it/infor/ Ontology/Papers/SCIE97.pdf. >. Acesso em: 30 jul. 2013.

HOUAISS, Instituto Antonio. Dicionário eletrônico Houaiss da língua portuguesa: versão 3.0. São Paulo: Objetiva, 2009.

KASAMA, Deni Yuzo et al. Do termo à estruturação semântica: representação ontológica do domínio da Nanociência e Nanotecnologia utilizando a Estrutura Qualia. Linguamática: Revista para o Processamento Automático das Línguas Ibéricas. v. 2, n. 3, p. 43-58, dez. 2010. Disponível em: <http://inguamatica.com/index.php/linguamatica/article/view/73>. Acesso em: 02 fev. 2011.

MAGNINI, Bernardo; SPERANZA, Manuela. Merging global and specialized linguistic ontologies. Proceedings of the Workshop Ontolex2002 Ontologies and Lexical Knowledge Bases, LREC, 2002, p. 43-48. Disponível em: <http://multiwordnet.fbk.eu/paper/ontomerge-ontolex. pdf. Acesso em: 01 fev 2011.

MEERSMAN, R. et. al. Data modelling versus ontology engineering. Bélgica: SIGMOD Records, v. 31, n. 4, p. 12-17, dez. 2002. Disponível em: <http://www.acm.org/sigmod/record/issues/0212/SPECIAL/2. Meersman.pdf.?. Acesso em 30 jul. 2013.

MOREIRA, W. Lexicologia, terminologia, ontologia e representação documentária: Estudos de interface por meio de análise de periódico de Ciência da Informação. Biblios: Revista de Bibliotecología y Ciencias de la Información, Peru, ano 8, n. 27, fev./mar., 2007. Disponível em: $<$ http://redalyc.uaemex.mx/redalyc/pdf/161/16102705.pdf $>$. Acesso em: 30 jul. 2013.

PINHEIRO, Wallace Anacleto. Busca em portais semânticos: uma abordagem baseada em ontologias. 2004. 170f. Dissertação (Mestrado em Sistemas e Computação) - Instituto Militar de Engenharia, Rio de Janeiro. Disponível em: http://www2.comp.ime.eb.br/dissertacoes/ 2004-Wallace_Pinheiro.pdf. Acesso em: 20 dez. 2010.

RASTIER, François et al. Sémantique pour l'analyse de la linguistique à l'informatique. Paris: Masson, 1994. 
SANTOS, Maria Cristina Andrade dos; VALE, Oto Araújo. Abordagem linguística no desenvolvimento de ontologias: proposta de construção de uma ontologia do domínio futebol. In: SEMINÁRIO DE PESQUISA EM ONTOLOGIA NO BRASIL, 2008, Niterói. Anais... Niterói, 2008.

SAUSSURE, Ferdinand de. Curso de Linguística Geral. São Paulo: Cultrix, 1999.

SOWA, J. F. Knowledge representation: logical, philosophical and computational foundations. California: Brooks/Cole Publishing Co., 2000. Disponível em: < http://www.jfsowa.com/ontology/>. Acesso em: 30 jul. 2013.

SWATOUT, W; TATE, A. Ontologies. IEEE Inteligent Systems \& their applications, v. 14, n. 1, jan/fev, 1999.

USCHOLD, Mike; JASPER, Robert. A framework for understanding and classifying ontology applications. In: WORKSHOP ON ONTOLOGY AND PROBLEM SOLVING METHODS: Lessons Learned and Future Trends, 1999. Proceedings... Stockholm, 1999. Disponível em: < http://CEURWS.org/Vol-18>. Acesso em: 15 jul. 2009.

XAVIER, Antonio Carlos. A era do bipertexto: linguagem e tecnologia. Recife: Universitária da UFPE, 2009.

Recebido para publicação em 5 de agosto de 2013 Aprovado em 2 de outubro de 2013 